\title{
Direct Chemical Analysis of UV Laser Ablation Products of Organic Polymers By Using Selective Ion Monitoring Mode in Gas Chromatography / Mass Spectrometry
}

\author{
Yeong Choi, Heewon Lee, Scott T. Fountain, and David M. Lubman \\ Department of Chemistry, The University of Michigan, Ann Arbor, Michigan, USA
}

\begin{abstract}
Trace quantities of laser ablated organic polymers were analyzed by using commercial capillary column gas chromatography/mass spectrometry; the instrument was modified so that the laser ablation products could be introduced into the capillary column directly and the constituents of each peak in the chromatogram were identified by using a mass spectrometer. The present study takes advantage of the selective ion monitoring mode for significantly improving the sensitivity of the mass spectrometer as a detector, which is critical in analyzing the trace quantities and confirming the presence or absence of the species of interest in laser ablated polymers. The initial composition of the laser ablated polymers was obtained by using an electron impact reflectron time-of-flight mass spectrometer and the possible structure of the fragments observed in the spectra was proposed based on the structure of the polymers. ( $\mathrm{f}$ Am Soc Mass Spectrom 1994, 5, 106-112)
\end{abstract}

$\mathrm{T}$ The interactions of UV laser radiation with organic polymers have been studied extensively for their potential applications in technology and medicine [1-12]. Technological applications include photolithography, a process widely used in semiconductor processing to pattern silicon, oxide, or metal surfaces by a procedure analogous to photography $[2$, 4], and medical applications include its use in cardiovascular and ophthalmologic surgeries [5-12]. Although physical aspects of laser ablation are relatively well understood $[3,4]$, direct chemical analysis of the ablation products is still a challenging task that needs to be explored [4]. Some difficulties associated with chemical analysis of the ablation products in these applications involve the complexity and small quantities of ablation products that may result. Even more problematic in some cases is the lack of a technique for direct chemical analysis of the laser-induced ablation products in trace quantities. Previous chemical analyses of laser ablation products of organic polymers have been performed employing indirect methods, that is, the laser ablation products were collected in a container and were transported to an instrument for analysis $[1-3,12]$. This procedure has the inherent problem of subjecting the results to uncertainties due to possible introduction of impurities and absorption of trace quantities of laser ablation products on the wall.

Address reprint requests to D. M. Lubman, Department of Chemistry, The University of Michigan, Ant Arbor, MI 48109.
A particular problem of interest in UV laserinduced ablation is the use of the ArF excimer laser $(\lambda=193 \mathrm{~nm})$ as a promising tool for etching and laser surgery. Previous studies have shown that, compared with other UV, infrared, or visible lasers, this far UV laser radiation can ablate specific areas with little thermal damage to the substrate [5-8]. Thus, the ArF excimer laser has been used extensively in corneal surgeries such as phototherapeutic or photorefractive keratectomy for its ability to precisely remove a predetermined amount of corneal tissue through a photochemical laser-tissue interaction [6-9]. More recent studies have shown that use of an appropriate masking polymeric fluid in excimer laser surgeries can result in improved smoothness of the corneal surface in these surgical procedures and thus there has been an effort to develop new polymer masks for this purpose [11, 12].

A drawback of the use of UV radiation for laserinduced ablation studies is the formation of photochemically induced products which may be toxic. This can become a serious problem when UV laser ablation is used in human subjects in surgical procedures. As an example, the masking polymers used in corneal surgery are similar to polyethylene glycol and may be produced by sequential addition of propylene oxide and ethylene oxide to propylene glycol [13]. In this case, UV laser ablation may conceivably produce ethylene oxide and other such products that are highly toxic and possibly carcinogenic, and are also generally highly reactive. If such species were produced in siz- 
able amounts, then this might preclude the use of these polymers in these surgical procedures. Thus, such problems have motivated us toward developing direct analytical methods for detecting and identifying the UV laser-induced ablation products of polymers.

In the present study, a commercial gas chromatography/mass spectrometry (GC/MS) system has been modified to directly analyze trace quantities of $\mathrm{ArF}$ excimer UV laser-induced ablation products. By using a mass selective detector (MSD), the capability of GC as a technique to separate and identify the trace quantities of laser ablation products is significantly enhanced. In particular, the present study takes advantage of the fact that obtaining the chromatogram in the selective ion monitoring (SIM) mode increases the sensitivity of the detector significantly, a desirable feature for analyzing the trace quantities of laser ablation species. By selecting the appropriate ions to be monitored in the SIM mode, only the species of interest may be detected and the signals due to background and impurities may be ignored. In addition, a direct laser ablation of polymers in a reflectron time-of-flight mass spectrometer (Re TOF-MS) with electron impact (EI) has been used as a complementary means of obtaining information on the laser ablation products of polymers. It was found that the GC/MS method in which helium was used as a carrier gas enhances detection of low mass species while ablation in vacuum in the Re TOFMS enhances detection of larger mass species.

\section{Experimental}

The LA/Re TOF-MS (laser ablation/Re TOF-MS) and the LA/GC/MS (laser ablation/GC/MS) experimental setups are described here. The first technique was used to obtain preliminary results on the separation and identification of the products from laser ablated polymers, and the other describes in detail the technique which was critical for the identification of the laser ablation products.

\section{Laser Ablation / Re TOF-MS}

For the preliminary study of identification of the laser ablation products of polymers, an Re TOF-MS was used. Because the instrumentation and operation of the Re TOF-MS used for the present study have been described in detail elsewhere [14, 15], only a brief description of the method will be presented here. The Re TOF-MS (R. M. Jordan Co., Grass Valley, CA) used in the present study is a standard commercial instrument. A small quantity of liquid sample was applied on the surface of a Macor (a machinable ceramic; Corning Glass Works, Corning, NY) probe tip to form a thin film. The thin film sample was ablated with an A.rF ( $\Lambda=193 \mathrm{~nm}$ ) excimer laser (Questek Mudel 2120). The laser beam (power density $=5.3 \times 10^{7} \mathrm{~W} / \mathrm{cm}^{2}$ ) was focused by a convex lens (focal length $=10 \mathrm{in}$.) placed outside the vacuum chamber for production of ablation species. The neutral species produced upon laser ablation were entrained in either a pulsed helium or nitrogen supersonic jet (source pressure $=1 \mathrm{~atm}$ ) as described previously $[14,15]$ and introduced into the ionization region through a skimmer. The neutral species were ionized in the TOF acceleration region by EI at $70 \mathrm{eV}$ with $1,4 \mathrm{~mA}$ emission current and were pulsed out toward the field-free region. These ions were then reflected by the reflectron, which acts as an ion mirror and were detected by a Chevron-type dual microchannel plate detector with $-3 \mathrm{kV}$ postacceleration. Ultimately, the spectra were obtained by using a LeCroy (Chestnut Ridge, NY) 9400 Digital Oscilloscope by signal averaging 50 spectra.

\section{Laser Ablation / GC/MS}

A Hewlett-Packard (Palo Alto, CA) GC (HP 5890 Series II)/MSD (HP 5971A) system was modified so that the laser ablation products might be introduced into the capillary column directly. Figure 1 shows an overview of the LA/GC/MS experimental setup. The capillary column used was HP-1 (cross-linked methyl silicone gum; $12 \mathrm{~m} \times 0.2 \mathrm{~mm} \times 0.33 \mu \mathrm{m}$ film thickness). Helium gas, filtered through a Gas-Dry Filter Trap (Chemical Research Supplies, Addison, IL), was used as a carrier gas in the capillary column.

A laser ablation cell was constructed from a brass Cajon (Macedonia, $\mathrm{OH}$ ) tee (i.d. $=0.25 \mathrm{in}$.), as shown in Figure 2. A hole was drilled on the flat side of the tee and a quartz window was glued in its place by using Torr Seal (Varian Associates, Walnut Creek, CA). The sample holder is a brass rod ( $d=0.25$ in.) with a hole at one end into which a Macor probe tip $(d=0.125$ in.) fits. The sample holder is inserted through the opening of the tee on the opposite side of the quartz window. Helium gas was continuously passed through the cell by using the two remaining openings to transport the laser ablation products into the capillary column via a 6-port external volume sample (EVS) injector (Valco Instruments Co., Houston, TX). The helium flow rate $(<1 \mathrm{ml} / \mathrm{min}$ ) was adjusted so that the maximum amount of laser ablation products were transported into the capillary column. The transfer line (stainless steel tubing; length $=10 \mathrm{~cm}$, o.d. $=1 / 16 \mathrm{in}$., i.d. $=0.02 \mathrm{in}$.) from the laser desorption cell to the EVS injector was designed to be as short as possible to ensure that the laser ablation products were efficiently transported. This transfer line and the loop of the EVS injector were ofter heated up to about $150^{\circ} \mathrm{C}$ by blowing hot air from a heater or by wrapping them with heating tapes. However, heating the transfer line and the loop did neither significantly increase the intensities of the fragments observed nor transport additional heavier fragments.

Comparisons of the retention times of the products generated by laser ablation with those of known compounds for identification are meaningful if and only if the chromatograms were obtained under identical ex- 


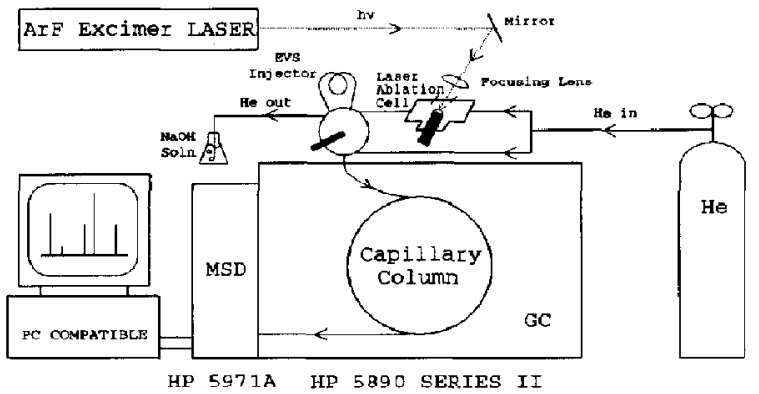

Figure 1. Overview of $\mathrm{LA} / \mathrm{GC} / \mathrm{MS}$ experiment.

perimental conditions. Therefore, when the chromatogram of a known compound was run, the sample holder was removed and a reservoir of the compound (either a liquid with sufficient vapor pressure or a gas) was connected in its place. This ensures the identical sample injection condition into the capillary column for both the known compounds and the laser ablation products.

A thin film prepared by applying a small quantity of liquid sample on the surface of a Macor probe tip was ablated for approximately 30 seconds at $10 \mathrm{~Hz}$ with an ArF $(\lambda=193 \mathrm{~nm}$ ) excimer laser (Questek model 2120). The laser beam (power density $=5.3 \times$ $10^{7} \mathrm{~W} / \mathrm{cm}^{2}$ ) was focused by a convex lens $(\hat{\mathrm{f}}=10 \mathrm{in}$.) placed outside the laser ablation cell so that the laser beam diameter was adjusted to cover the probe tip ( $d=2 \mathrm{~mm}$ ) for the maximum production of the fragments. The urganic polymers studied, such as poluxamer 407 solution, were applied directly onto the probe tip whereas polyethylene glycol (PEG) 1450 (a white solid) was dissolved in a small volume of methanol and then applied on the probe tip. Before laser ablation, the methanol was evaporated completely, leaving only a thin film of PEG 1450 on the probe tip.

The products from laser ablation of the polymers continuously pass through the loop of the EVS injector made of a stainless steel tubing (length $=10 \mathrm{~cm}$, o.d. $=1 / 16$ in., i.d. $=0.02$ in., vol. $=8 \mu \mathrm{l} / \mathrm{cm}$ ). The EVS injector can be set in either LOAD or INJECT position. In LOAD position, shown in Figure 3a, the products continuously pass through the loop, carried

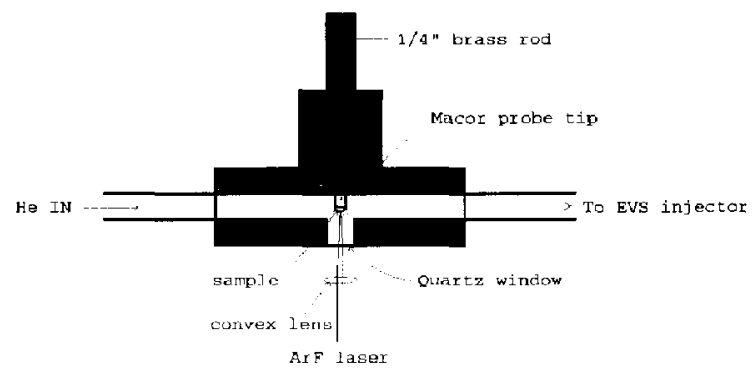

Figure 2. Laser ablation cell.

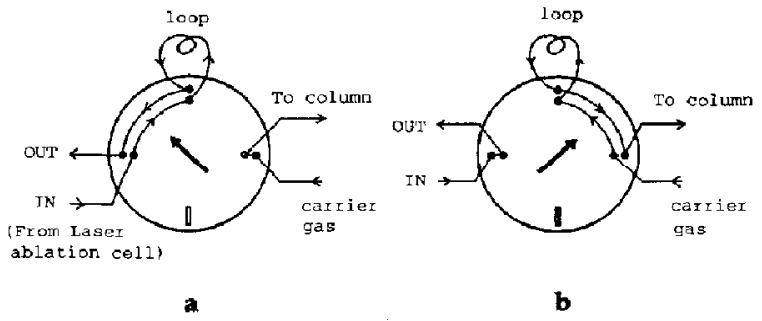

Figure 3. EVS injector. (a) LOAD position; (b) INJECT position.

by helium gas, and exit the loop via the OUT tubing. The end of the OUT tubing is immersed in $\mathrm{NaOH}$ solution to prevent a direct exposure of the products into the air. Bubbling the helium gas carrying products through $\mathrm{NaOH}$ solution also provides a visual means of checking the helium flow rate. When the EVS injector is set in INJECT position, shown in Figure 3b, helium carrier gas for the column first passes through the loop, thus sweeping a portion of the laser ablation products that is present at that particular instance in the loop of the injector into the column. As soon as the products are swept out of the loop, the EVS injector is set back to the LOAD position and the measurement of the retention time of the species in the capillary column begins.

For all the experiments in the present study, the oven, injector, and detector (interface between GC and mass spectrometer) temperatures were 40 (isothermal), 50 , and $280^{\circ} \mathrm{C}$, respectively, and the helium carrier gas pressure was 2 psi. These were the optimal conditions for separation and detection of the laser ablation products determined after experimenting with various conditions. Since the quantities of the laser ablation products of the polymer were expected to be extremely small, the products were introduced into the capillary column in a splitless mode.

Hewlett-Packard MS ChemStation Data System running within MICROSOFT WINDOWS ${ }^{\mathrm{TM}} 3.1$ on a PC compatible (Intel 80486DX processor, 33MHz), a versatile graphical user interface, was used for the data acquisition and analysis. This software was also used for tuming the MSD by using perfluoru-tributyl-amine as an internal standard and controlling various temperatures on the GC. By using the Chemstation Data System, the background was subtracted from the raw chromatograms to obtain the chromatograms resulting from the pure species. To minimize the background, the capillary column was baked ovemight at $100^{\circ} \mathrm{C}$ or higher with helium gas flowing through it continuously prior to the experiment. The experiments were repeated several times on the same sample to ensure the reproducibility of the results.

The polymers studied in this work included Flowgel $^{\circledR}$, which has the potential to be used as a masking fluid in corneal laser surgical procedures. The Flowgel consists of poloxamer 407 solution (about 20\% by weight) which has the generic formula of 
$\mathrm{HO}\left[\mathrm{CH}_{2} \mathrm{CH}_{2} \mathrm{O}\right]_{b}\left[\mathrm{CH}\left(\mathrm{CH}_{3}\right) \mathrm{CH}_{2} \mathrm{O}\right]_{a}\left[\mathrm{CH}_{2} \mathrm{CH}_{2} \mathrm{O}\right]_{b} \mathrm{H}$ [13]. In addition, PEG 1450 was also studied for comparisons with poloxamer. Acetaldehyde (liquid; $99 \%$ purity) and ethylene oxide (gas; $99.7 \%$ purity) were purchased from Aldrich Chemical Co. (Milwaukee, WI) and AGA Specialty Gas Co. (Maumee, OH), respectively, and were used without further purification.

\section{Results and Discussion}

\section{Laser Ablation/Re TOF-MS}

Figure 4 shows the mass spectrum of poloxamer obtained by using Re TOF-MS with EI detection. Those peaks that also appeared in the background are indicated with asterisks above the peaks and are not considered as the fragments from the laser ablation of poloxamer. These peaks include $\mathrm{CO}_{2}^{+}, \mathrm{N}_{2}^{+}$, and $\mathrm{H}_{2} \mathrm{O}^{+}$. The most intense peak from the poloxamer itself is $m / z 29$, and other peaks observed are $m / z 12,13,26$, $27,30,31,39,41,42,43,45,55,57,58,59,69,71,73,85$, 87, and 89. It was observed that as soon as the poloxamer 407 solution was introduced into the vacuum chamber for laser ablation, water was quickly evaporated, leaving a thin film of white residue which was mainly poloxamer. In comparison, Figure 5 shows the mass spectrum of PEG 1450 obtained by using Re TOF-MS. The most intense peak from PEG 1450 is $\mathrm{m} / \mathrm{z}$ 45 , and other peaks observed are $m / z 1,2,26,27,30$, $57,58,59,71,73,87,89,101$, and 103. As expected from the structural similarities, the mass spectra of poloxamer 407 solution and PEG 1450 have many common fragmentation products. Most of the ion peaks observed in the mass spectra of both poloxamer and PEG 1450 correspond to the fragments containing hydrogen, carbon, and oxygen atoms, and the possible mass assignments corresponding to these products are shown in Table 1. For example, the most intense peaks for the chromatograms of poloxamer $(m / z 29)$ and PEG 1450 $(m / z 45)$ correspond to a mixture of the fragments, $\mathrm{HCO}-$ and $\mathrm{CH}_{3} \mathrm{CH}_{2} \rightarrow$, and the fragment, $\mathrm{HOCH}_{2} \mathrm{CH}_{2}-$, respectively, based on the structure of these polymers.

\section{POLOXAMER}

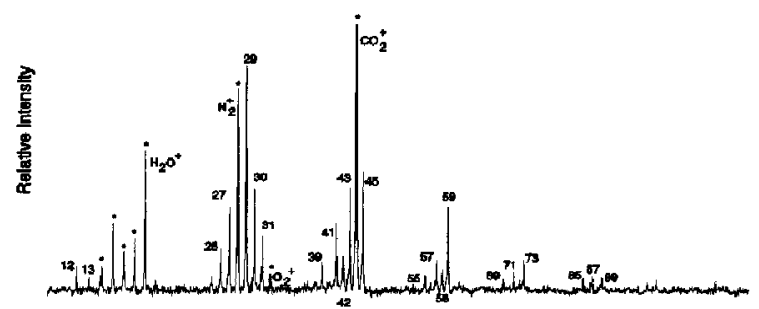

Figure 4. TOF mass spectrum of poloxamer.
PEG 1450

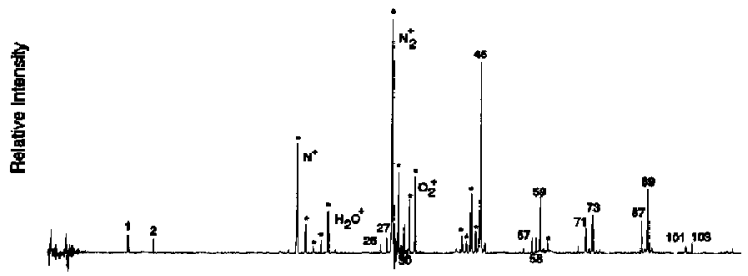

Figure 5. TOF mass spectrum of PEG 1450.

Recently, a two-step laser desorption/laser ionization technique using a TOF-MS as a detector has been used for the characterization of aromatic polymers [16] and the analysis of rubber vulcanizates [17] where resonant-enhanced multiphoton ionization (REMPI) at $\lambda=266 \mathrm{~nm}$ and other wavelengths were used for the ionization of the compounds. However, since poloxamer and PEG 1450 examined in the present study are not aromatic, the ionization of these compounds by $\lambda=266 \mathrm{~nm}$ can be only a nonresonant procedure and, consequently, was not expected to be very efficient. Indeed, no signal was ubserved in our experiments when REMPI at $\lambda=266 \mathrm{~nm}$ was used for ionization.

\section{Laser Ablation / GC / MS}

One of the shortcomings of using Re TOF-MS to analyze the products from the laser ablation of polymers is that the fragments of different masses produced by laser ablation are introduced into the ionization region at the same time. Thus, it becomes difficult to identify the parent species of the inns detected without some type of tandem mass spectrometry device. The infor-

Table 1. Proposed fragments from poly(ethylene glycol) and poloxamer

\begin{tabular}{cl}
\hline$m / z$ & \multicolumn{1}{c}{ Proposed fragment } \\
\hline \hline polylethylene glycol): & $\mathrm{H}-\left[\mathrm{OCH}_{2} \mathrm{CH}_{2}\right]_{\mathrm{a}}-\mathrm{OH}$ \\
30 & $-\mathrm{OCH}_{2}-$ \\
45 & $\mathrm{HOCH}_{2} \mathrm{CH}_{2}-$ \\
61 & $\mathrm{HOCH}_{2} \mathrm{CH}_{2} \mathrm{O}-$ \\
74 & $-\mathrm{OCH}_{2} \mathrm{CH}_{2} \mathrm{OCH}_{2}-$ \\
89 & $\mathrm{HOCH}_{2} \mathrm{CH}_{2} \mathrm{OCH}_{2} \mathrm{CH}_{2}-$ \\
72 & $-\mathrm{CH}_{2} \mathrm{CH}_{2} \mathrm{OCH}_{2} \mathrm{CH}_{2}-$ \\
58 & $-\mathrm{CH}_{2} \mathrm{OCH}_{2} \mathrm{CH}_{2}-$ \\
44 & $-\mathrm{CH}_{2} \mathrm{OCH}_{2}-$ \\
poloxamer: $\mathrm{HO}-\left[\mathrm{CH}_{2} \mathrm{CH}_{2} \mathrm{Ol}_{3} \mathrm{ICH}_{2} \mathrm{CH}_{3}\right) \mathrm{CH}_{2} \mathrm{OJ}_{6} \mathrm{ICH}_{2} \mathrm{CH}_{2} \mathrm{OI}-\mathrm{H}$ \\
58 & $\left.-\mathrm{CHCH}_{3}\right) \mathrm{CH}_{2} \mathrm{O}-$ \\
72 & $\left.-\mathrm{CH}_{3} \mathrm{CH}_{3}\right) \mathrm{CH}_{2} \mathrm{OCH}_{2}-$ \\
86 & $\left.-\mathrm{CHCH}_{3}\right) \mathrm{CH}_{2} \mathrm{OCH}_{2} \mathrm{CH}_{2}-$ \\
102 & $\left.-\mathrm{CHCH}_{3}\right) \mathrm{CH}_{2} \mathrm{OCH}_{2} \mathrm{CH}_{2} \mathrm{O}-$ \\
\hline
\end{tabular}

"The proposed polylethylene giycoll fragments afso apply to the poloxamer sample due to their structural similarities. 
mation obtained by using a capillary column GC complements the information obtained from the Re TOF-MS study because capillary column GC can, in principle, separate the fragments in time under appropriate experimental conditions.

To identify the major laser ablation products, a series of chromatograms were obtained in the total ion mode (TIM) by scanning a small mass range at a time up to $m / z$ 105. Although the ions with $m / z 28,29,32$, 40 , and 44 had been observed in the chromatograms obtained in the TIM, they were not collected here because they could originate from the background. When the chromatogram was obtained in the TIM $(\mathrm{m} / z$ 14-60, Figure 6$)$, only one dominant water peak was observed at the retention time range $27.0-31.0$ seconds, as might be expected from the composition of poloxamer 407 solution (about $80 \%$ water by weight). Compared with water, the relative abundance of the other laser ablated products of poloxamer is several orders of magnitude smaller; therefore, it is almost impossible to detect these species in the TIM over a wide mass range. However, when the chromatogram of poloxamer 407 solution was obtained in the SIM mode collecting only the ions of $m / z 26,27,39,41,42$, and 43, thereby excluding the interse signal due to water, it was found that there are several peaks with much smaller intensities buried in the intense water peak, as shown in Figure 7. The fourth peak, $C_{,}$consists of ions with $m / z 27$ and 43 , as well as several other ions which are not shown in Figure 7 (e.g., $m / z$ 57 and 58), but the abundance of the ions that constitute the peak $C$ is so small that they were not consistently reproducible. The results are summarized in Table 2.

As mentioned previously, one of the main purposes of the present study was to determine if the laser ablation products of poloxamer 407 solution included toxic products such as ethylene oxide, a building block for poloxamer. From a structural consideration, another possible laser ablation product of poloxamer is

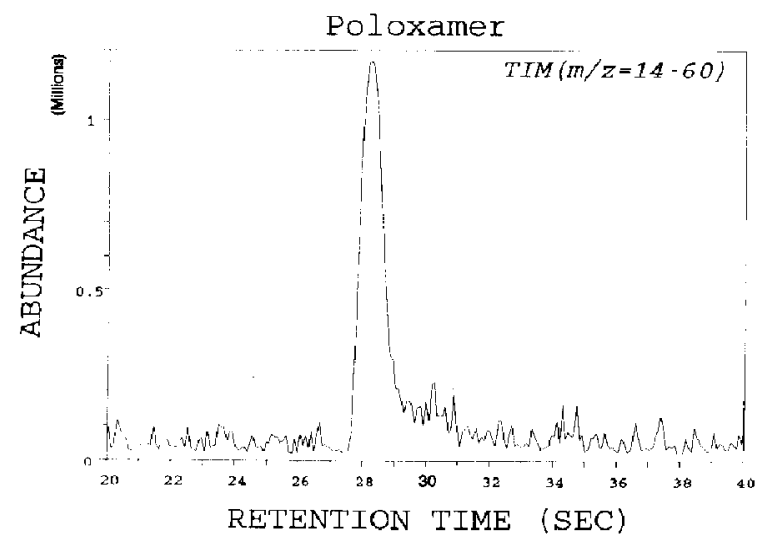

Figure 6. GC /MS of laser ablated poloxamer obtained in TIM $(m / z 14-60)$.

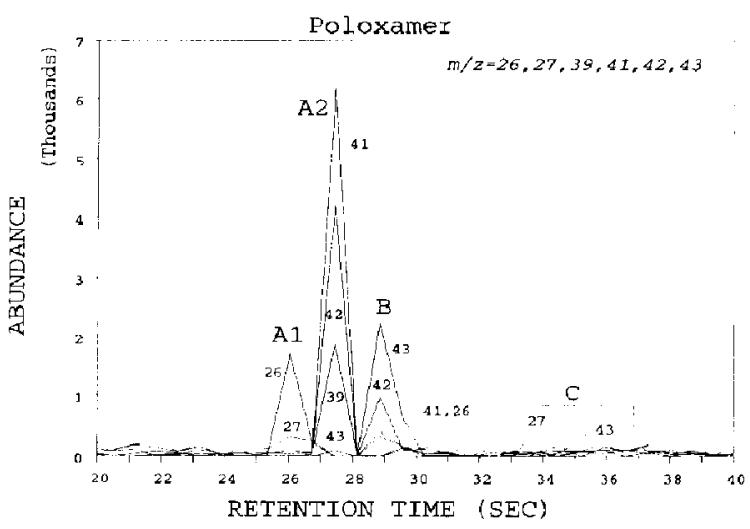

Figure 7. An overlay GC/MS of laser ablated poloxamer for the ions $m / z 26,27,39,41,42$, and 43 .

acetaldehyde, an isomer of ethylene oxide. To determine if any one of the four peaks observed in the chromatogram of poloxamer 407 solution corresponds to either, or both, of the isomers, these two compounds were introduced into the capillary column at the same time under the identical experimental conditions and an overlay ion chromatogram of $m / z 26,41,42$, and 43 was obtained, as shown in Figure 8 . The chromatogram of the acetaldehyde/ethylene oxide mixture shows two well-resolved peaks at the retention times of 28.8 and 30.3 seconds corresponding to acetaldehyde and ethylene oxide, respectively.

Because of their structural similarities, EI ionization of both acetaldehyde and ethylene oxide produce identical fragments, $m / z 26,41,42$, and 43 . These ions correspond to $\mathrm{C}_{2} \mathrm{H}_{2}^{+}, \mathrm{C}_{2} \mathrm{HO}^{+}, \mathrm{C}_{2} \mathrm{H}_{2} \mathrm{O}^{+}$, and $\mathrm{C}_{2} \mathrm{H}_{3} \mathrm{O}^{+}$. respectively, and in both isomers, the $\mathrm{C}_{2} \mathrm{H}_{3} \mathrm{O}^{+}(\mathrm{m} / \mathrm{z}$ 43) ion peak is most intense, followed by the $\mathrm{C}_{2} \mathrm{H}_{2} \mathrm{O}^{+}$ $(\mathrm{m} / z=42)$ ion peak. However, one major difference

Table 2. Peaks observed in the GC of the species from laser-ablated poloxamer

\begin{tabular}{lcll}
\hline Peak & $\begin{array}{c}\text { Retention time } \\
\text { at apex (seconds) }\end{array}$ & $\begin{array}{c}m / z \\
\text { observed }\end{array}$ & \multicolumn{1}{c}{$\begin{array}{c}\text { Possible } \\
\text { species }\end{array}$} \\
\hline \hline A1 & 26.0 & 27 & $\mathrm{C}_{2} \mathrm{H}_{3}^{+}$ \\
& & 26 & $\mathrm{C}_{2} \mathrm{H}_{2}^{+}$ \\
A2 & 27.5 & 43 & $\mathrm{C}_{3} \mathrm{H}_{7}^{+}$ \\
& & 42 & $\mathrm{C}_{3} \mathrm{H}_{6}^{+}$ \\
& & 41 & $\mathrm{C}_{3} \mathrm{H}_{5}^{+}$ \\
& & 39 & $\mathrm{C}_{3} \mathrm{H}_{3}^{+}$ \\
B & 28.8 & 43 & $\mathrm{C}_{2} \mathrm{H}_{3} \mathrm{O}^{+}$ \\
& & 42 & $\mathrm{C}_{2} \mathrm{H}_{2} \mathrm{O}^{+}$ \\
& & 41 & $\mathrm{C}_{2} \mathrm{HO}^{+}$ \\
& & 26 & $\mathrm{C}_{2} \mathrm{H}_{2}^{1}$ \\
C & $32.0-39.0$ & $(581$ & $\mathrm{C}_{2} \mathrm{H}_{2} \mathrm{O}_{2}^{+}$ \\
& & $(57)$ & $\mathrm{C}_{2} \mathrm{HO}_{2}^{+}$ \\
& & 43 & $\mathrm{C}_{3} \mathrm{H}_{7}^{+}, \mathrm{C}_{2} \mathrm{H}_{4} \mathrm{O}^{+}$ \\
& & 27 & $\mathrm{C}_{2} \mathrm{H}_{3}^{+}$ \\
\hline
\end{tabular}




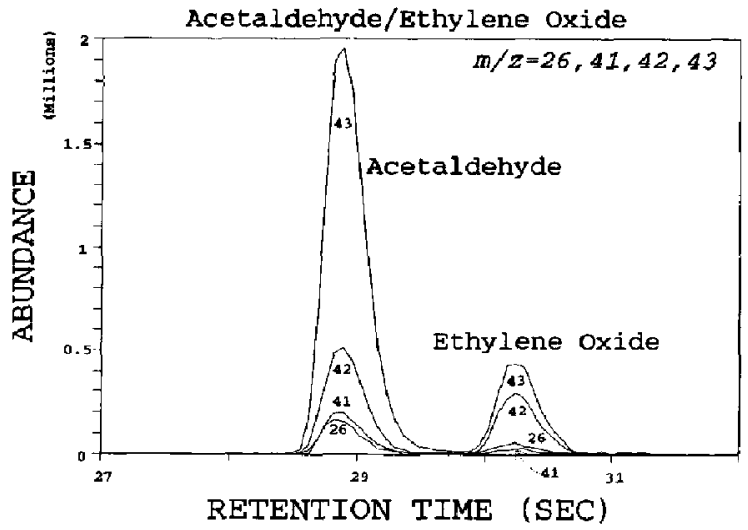

Figure 8. An overlay GC/MS of acetaldehyde/ethylene oxide mixture for the ions $m / z 26,41,42$, and 43 .

between acetaldehyde and ethylene oxide is the relative intensity ratio of the fragments produced, particularly the ratio, $\left[\mathrm{C}_{2} \mathrm{H}_{3} \mathrm{O}^{+}(m / z 43)\right] /\left[\mathrm{C}_{2} \mathrm{H}_{2} \mathrm{O}^{+}(m / z\right.$ 42)]. In all the chromatograms of acetaldehyde, ethylene oxide, and the mixture of these two isomers that we have obtained, we found that the relative intensity ratio of the fragments, $\left[\mathrm{C}_{2} \mathrm{H}_{3} \mathrm{O}^{+}(m / z 43)\right] /\left[\mathrm{C}_{2} \mathrm{H}_{2} \mathrm{O}^{+}\right.$ $(m / z 42)$ ], is always larger than 2 for acetaldehyde whereas the ratio is always much smaller than 2 for ethylene oxide.

Comparing the chromatogram of laser ablated poloxamer in Figure 7 with that of acetaldehyde/ethylene oxide mixture in Figure 8, the following observations are made:

1. The peak B in Figure 7 has the same fragmentation pattern and the same most abundant ion $(\mathrm{m} / \mathrm{z} 43)$ as the acetaldehyde peak.

2. The peak $B$ in Figure 7 has the same retention time as acetaldehyde (i.e., 28.8 seconds).

3. The relative intensity ratio, $\left[\mathrm{C}_{2} \mathrm{H}_{3} \mathrm{O}^{+}(\mathrm{m} / \mathrm{z}\right.$ 43)] $/\left[\mathrm{C}_{2} \mathrm{H}_{2} \mathrm{O}^{+}(m / z 42)\right]$, for the peak $\mathrm{B}$ in Figure 7 is larger than 2 (about 2.3), consistent with the acetaldehyde peak.

4. The relative intensity ratio, $\left[\mathrm{C}_{2} \mathrm{H}_{2} \mathrm{O}^{+}(\mathrm{m} / \mathrm{z}\right.$ 42)] $/\left[\mathrm{C}_{2} \mathrm{HO}^{+}(\mathrm{m} / \mathrm{z} 41)\right]$ for the peak $\mathrm{B}$ in Figure 7 is about 3 , again comparable to the acetaldehyde peak.
Based on observations 2-4, the peak B in Figure 7 is identified as that due to acetaldehyde, not ethylene oxide. To verify that the peak $B$ in Figure 7 indeed corresponds to acetaldehyde, an extensive literature search has been performed to locate possible compounds that provide similar fragmentation patterns and intensity ratios [18]. The only other compound that provides a similar fragmentation pattern with the peak $B$ in Figure 8 is propane, but with much different intensity ratios (i.e., $\left[\mathrm{C}_{2} \mathrm{H}_{3} \mathrm{O}^{+}(m / z \quad 43)\right] /\left[\mathrm{C}_{2} \mathrm{H}_{2} \mathrm{O}^{+}\right.$ $(m / z 42)]=1.5$ and $\left[\mathrm{C}_{2} \mathrm{H}_{2} \mathrm{O}^{+}(m / z 42)\right] /\left[\mathrm{C}_{2} \mathrm{HO}^{+}\right.$ $(m / z 41)] \simeq 0.4)$ [18], thus precluding it as a possible compound. These results are summarized in Table 3.

As can be deduced from the abundance of the ions observed in Figure 7, as compared, for example, with that of the acetaldehyde/ethylene oxide mixture shown in Figure 8, the amount of laser ablation products is very small. In the present experimental setup, the laser ablation products were continuously passed through the loop of the EVS injector by helium gas and only a small fraction of the total species produced was introduced into the capillary column GC for analysis. Therefore, it was not possible to quantify the exact total amount of laser ablation products. To estimate the detection limit of the instrument, acetaldehyde was successively diluted in methanol and the intensity of the $\left[\mathrm{C}_{2} \mathrm{H}_{3} \mathrm{O}^{+}(\mathrm{m} / z\right.$ 43) $]$ ion peak of the diluted acetaldehyde in GC was monitored until the signal-tonoise ratio was about 3 . The detection limit obtained in this way is estimated to be about 4 nanomole, whereas the intensity of the $\left[\mathrm{C}_{2} \mathrm{H}_{3} \mathrm{O}^{+}(m / z 43)\right]$ ion peak of the acetaldehyde from laser ablation of poloxamer 407 solution corresponds to about 9 nanomole, based on the relative intensity of the peaks.

The chromatogram of laser ablated PEG 1450 (Figure 9) obtained in the SIM mode for the ions $m / z 26$, $27,39,41,42$, and 43 , shows similar features as that of poloxamer, although the relative intensities of the peaks are slightly different. As in the case of poloxamer, the chromatogram of laser ablated PEG 1450 also shows four major peaks, A1, A2, B, and C, at the retention times of $26.0,27.5,28.8$, and $33.0-37.0 \mathrm{sec}-$ onds, respectively. These are, in fact, the identical peaks with the identical retention times as those of poloxamer but with different relative intensities. The second peak, A2, which consists of the ions $m / z 39$,

Table 3. Comparison of the chromatograms of acetaldehyde/ethylene oxide mixture and laser-ablated poloxamer

\begin{tabular}{|c|c|c|c|}
\hline Compound & $\begin{array}{c}\text { Retention time } \\
\text { at apex (seconds) }\end{array}$ & $\frac{\left[\mathrm{C}_{2} \mathrm{H}_{3} \mathrm{O}^{+}(\mathrm{m} / \mathrm{z} 43)\right]}{\left[\mathrm{C}_{2} \mathrm{H}_{2} \mathrm{O}^{+}(\mathrm{m} / \mathrm{s} 42)\right]}$ & $\frac{\left[\mathrm{C}_{2} \mathrm{H}_{2} \mathrm{O}^{+}(\mathrm{m} / \mathrm{z} 42)\right]}{\left[\mathrm{C}_{2} \mathrm{HO}^{+}(\mathrm{m} / \mathrm{z} 41)\right]}$ \\
\hline Acetaldehyde & 28.8 & $>2$ & $\simeq 3$ \\
\hline Ethylene oxide & 30.3 & $<2$ & $\simeq 10$ \\
\hline Propane $^{a}$ & - & $<2(1.5)$ & $<1(0.4)$ \\
\hline Peak B (Poloxamer) & 28.8 & $>2$ & $\simeq 3$ \\
\hline
\end{tabular}

From ref 18. 


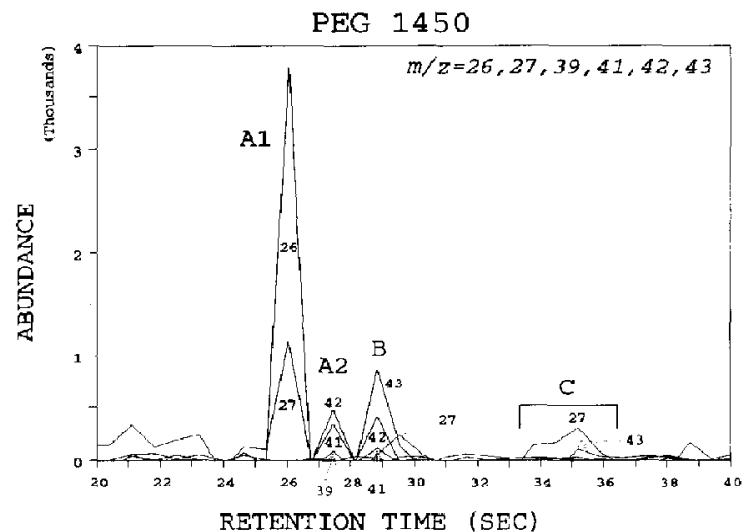

Figure 9. An overlay GC/MS of laser ablated PEG 1450 for the ions $m / 226,27,39,11,12$, and 13 .

41,42 , and 43 , is the most intense peak in the case of poloxamer, whereas for PEG 1450, the first peak, A1, which consists of the ions $m / z 26$ and 27 , is the most intense peak.

\section{Conclusions}

The present study provides significant insight into the composition of the laser ablated poloxamer which has the potential use as a masking fluid in corneal laser surgery. The initial information on the laser ablated poloxamer was obtained by using an EI Re TOF-MS, whereas detailed chernical analysis was performed by using the SIM mode in the modified GC/MS by taking advantage of its high sensitivity. The information obtained in the present study includes the confirmation of the presence of acetaldehyde and the absence of ethylene oxide from the laser ablation of poloxamer. Three additional fragments have been separated in the capillary column which have the different compositions consisting of carbon, hydrogen, and oxygen. Although the modified GC/MS used in the present study could separate the laser ablated poloxamer, it has been shown to be effective only for the detection of low mass species. Larger mass species would be defected if softer ionization techniques such as chemical ionization were utilized. One of the major reasons for the low sensitivities of both MSD and TOF-MS toward higher mass ions may be due to the laser power density used for the laser ablation of poloxamer in the present study, which is high enough to favor the low mass fragmentation. The significance of the present GC/MS experimental setup is its capability to directly analyze trace amounts of laser ablation products, thus completely eliminating the uncertainties due to possible introduction of impurities that is often problematic in an indirect analysis of trace quantities. Further study to quantify the trace amount of the laser ablation products of these polymers is planned.

\section{References}

1. Srinivasan, R.; Leigh, W. J. J. Am. Chem. Soc. 1982, 104, 6784-6785.

2. Brannon, J. H.; Lankard, J. R.; Baise, A. I.; Burns, F.; Kaufman, J. J. Appl. Phys. 1985, 58, 2036-2043.

3. Yeh, J. T. C. J. Vac. Sci. Technol. A 1986, 4, 653-658.

4. Srinivasan, R.; Braren, B. Chem. Rev. 1989, 89, 1303-1316.

5. Singleton, D. L.; Paraskevopoulos, G.; Jolly, G. S.; Irwin, R. S.; McKenney, D. J.; Nip, W. S.; Farrell, E. M.; Higginson, L. A. J. Appl. Phys. Lett. 1986, 48, 878-880.

6. Sher, N. A.; Bowers, R. A.; Zabel, R. W.; Frantz, J. M.; Eiferman, R. A.; Brown, D. C.; Rowsey, J. J.; Parker, P.; Chen, V.; Lindstrom, R. L. Arch. Ophthalmol 1991, 109, 491-498.

7. Puliafito, C. A.; Stern, D.; Krueger, R. R.; Mandel, E. R. Arch. Ophthalmol. 1987, 105, 1255-1259.

8. Marshall, J.; Trokel, S.; Rothery, S.; Schubert, H. Ophthalmol. $1985,92,749-758$.

9. Deutsch, T. F. Phys. Today 1988, October, 56-63.

10. Kornmell, E. W.; Steinert, R. F.; Puliafito, C. A. Arch. Ophthaimol. 1991, 109, 860-863.

11. Englanoff, J. S., Kolahdouz-Isfahani, A. H.; Moreira, H.; Cheung, D. T.; Nimni, M. E.; Trokel, S. L.; McDonnell, P. J. Ophthalmol. 1992, 99, 1201-1208.

12. Kahle, G.; Stödter, H.; Seller, T.; Wollensak, J. Invest, Ophthalmol. Vis. Sci. 1992, 33, 2180-2184.

13. Henry, R. L. Private communication, Mediventures, Inc., 1990.

14. Fountain, S. T.; Lubman, D. M. Anal. Chem, 1993, 65, $1257-1266$.

15. Lustig, D. A.; Lubman, D. M. Rev. Sci. Instrum. 1991, 62, 9.57-96?.

16. Lustig, D. A.; Lubman, D. M. Int. J. Mass Spectrom. Ion Processes 1991, 107, 265-280.

17. Lykke, K. R.; Parker, D. H.; Wurz, P.; Hunt, J. E.; Pellin, M. J.; Gruen, D. M,; Hemminger, J. C.; Lattimer, R. P. Anal. Chem. 1992, 64, 2797-2803.

18. Eight Peak Index of Mass Spectra, 3rd ed.; The Royal Society of Chemistry: Nottingham, UK, 1983. 